\title{
MEMBANGUN PROXY SERVER SEBAGAI PENYARING KONTEN DAN MANAJEMEN AKSES JARINGAN INTERNET PADA PT. INDOMARINE SURABAYA
}

\author{
Ahmad Irsyadur $\mathrm{R}^{1}$, Fitri Marisa ${ }^{2}$ \\ 19ahmad.irsyad04@gmail.com, ${ }^{2}$ fitrimarisa@widyagama.ac.id \\ Teknik Informatika, Universitas Widyagama Malang
}

\begin{abstract}
PT.Indomarine a privately omned company engaged in the Manufacture and Boiler Construction, which in activity internet usage there are limitations according to applicable SOP, SOP rules in a regulation of companies to grant access to a particular term, for example, could access the internet only managerial level and above as applied recenty in the environment PT.Indomarine Corp. It is aimed at focus more of its employees to do work and avoid the theft of data from internet access. With such circumstances this system proxy server becomes the best solution for the use of filter.
\end{abstract}

Keywords: proxy server, cache, internet.

\section{PENDAHULUAN}

Teknologi informasi yang berkembang pesat dewasa ini, telah mendorong percepatan di berbagai bidang. Hal ini juga yang menyebabkan munculnya kemajuan pada perangkat lunak dan diimbangi pula dengan kemajuan dan kecanggihan teknologi beserta perangkat kerasnya. Secara langsung ataupun tidak, teknologi informasi telah menjadi bagian penting dari berbagai bidang kehidupan. Karena banyak kemudahan yang ditawarkan, teknologi informasi hampir tidak dapat dilepaskan dari berbagai aspek kehidupan manusia. Salah satunya cara ntuk mendapatkan informasi yang paling murah, cepat, terbaru adalah dengan menggunakan internet. Sekarang ini internet merupakan suatu kebutuhan dalam berbagai informasi ataupun mencari informasi. Proxy server merupakan sebuah perangkat lunak berbasis server yang dapat mengatur pemanfaatan internet, membagi sumber daya yang dimiliki dan meningkatkan kecepatan koneksi Internet dengan mengurangi permintaan akses secara langsung ke jaringan Internet dengan memanfaatkan cache Internet. Sehingga akses Internet dapat di kontrol dan dimonitoring secara baik.

Namun belakang ini banyak organisasi, baik dibidang pendidikan, pemerintahan, privat maupun komersial berusaha membatasi akses para penggunanya ke internet (terutama web) dengan alasan bandwidth yang dimiliki mulai terasa lambat ketika para penggunanya mulai banyak menggunakan web, dan juga ada sebuah peraturan dari perusahaan untuk memberikan akses kepada jabatan tertentu, misalnya yang bisa mengakses internet hanya level managerial keatas seperti yang diterapkan baru-baru ini di lingkungan PT.Indonesian Marine. Hal ini bertujuan untuk lebih menfokuskan para karyawan untuk melakukan pekerjaan dan menghidari pencurian data dari akses internet.

Dengan latar belakang diatas penulis mencoba membangun dan menerapkan proxy server ini dilingkungan PT.Indonesian Marine.

\section{TINJAUAN PUSTAKA}

\section{A. Jaringan Komputer}

Jaringan merupakan kumpulan dari beberapa computer dan peralatan penunjang lainnya yang terhubung dalam satu kesatuan dan saling terhubung didalamnya dapat saling bertukar informasi dan dalam kabel perantara yang menghuungkannya atau melauli gelombang elektronik.User computer dapat melakukan pencetakan dengan menggunakan satu printer yang digunakan secara bersamasama dalam sebuah jaringan. Selain itu user dapat menggunakan dan menjalakan hardware dan software secara bersama. Komputer yang terhubung didalam sebuah jaringan disebut node. Dalam satu jaringan bisa terdiri dari beberapa node, bahkan puluhan, ratusan, ribuan, atau jutaan.

\section{B. Sejarah Jaringan \\ Dahulu komunikasi yang melibatkan computer masih dilakukan secara manual dengan manusia sebagai media komunikasinya}


yaitu dengan manusianya sendiri yang membawa intruksi-intruksi antar computer. Hingga akhirnya George Stibitz pada akhir tahun 1940-an sukses memanfaatkan sebuah mesin teletype untuk mengirimkan pesan intruksi dari komputernya ke computer ini. Maju lagi hingga tahun 1964 dimana metode system Time Sharing System mulai gencar digarap.Kemudian ditahun 1969 UCLA (University Of California at Los Angeles), SRI (Stanford Research Institute), University of California at Santa Barbara, dan University of Utah berhasil menerapkan jaringan computer dan mulai berhubungan menggunakan jaringan ARPAnet.

\section{Ubuntu}

Ubuntu adalah system operasi turunan dari distro Linux jenis Debian unstable (sid), Ubuntu merupakan project untuk komunitas, yang bertujuan untuk menciptkan sebuah system operasi beserta dengan paket aplikasinya yang bersifat free dan open source, karena Ubuntu mempunyai prinsip untuk selamanya bersifat gratis (free of change) dan tidak ada tambahan untuk versi enterprise edition. Ubuntu memiliki berbagai kelebihan distribusi debian diantaranya adalah (Sandy Arjuni, 2010:2) :

1. Pemaketan (Packaging).

2. Pemilihan aplikasi yang luas (Application Choice).

3. Siklus pembaharuan dilakukan secara rutin (Updates).

4. Dikenal stabilitas dan kualitasnya terutama di sisi server (Stability and quaility).

\section{Server}

Menurut Purbo (2008:1), sebuah server (biasanya disebut server aplikasi) adalah sebuah program aplikasi yang menerima sambungan untuk permohonan servis dan memberikan kembali respons. Sebuah server aplikasi dapat dijalankan pada computer yang sama dengan client yang menggunakan server tersebut, atau dapat tersambung melalui jarignan computer.

Server computer adalah system computer yang dibuat untuk menjalankan aplikasi server. Sebuah computer server yang dialokasikan untuk menjalankan sebuah aplikasi server yang spesifik sering kali disebut dengan nama aplikasi tersebut. Contohnya, jika software Apache HTTP server dijalankan dikomputer server perusahaan, maka biasanya disebut wes server saja.

Menurut Firdian, Server adalah sebuah system computer yang menyediakan jenis layanan tertentu dalam sebuah jaringan computer. Server didukung dengan prosesor yang bersifat scalable system operasi khusus, yang disebut sebagai system operasi jaringan atau network operating system. Sistem juga menjalankan perangkat lunak administrative yang mengontrol akses terhadap didalamnya, seperti halnya berkas atau alat pencetakan (printer), dan memberikan akses kepada workstation anggota jaringan.

CorelDRAW Versi 5 menambahkan integrasi dengan XML, Generator, dan ActionScript. Penetrasi browser terus meningkat hingga kini mencapai 96\%.Flash Player telah tersedia untuk berbagai platform: Windows, Mac, Unix,BeOS, hingga OS/2 dan PocketPC.Jonathan Gay kini bekerja sebagai developer untuk Macromedia. Adobe Flash (dahulu bernama Macromedia Flash dikarenakan Macromedia yang meruakan produsen pembuat flash professional kini telah merjer dengan adobe corp, perubahan terjadi pada macromedia flashseries 9 menjadi Adobar Flash CS3 pada April 16, 2007) merupakan tools yang dikembangkan untuk membuat berbagai aplikasi berbasis internet.

\section{E. Client Server}

Sistem client-server dapat diterapkan dengan teknologi internet, di mana terdapat suatu unit computer yang berfungsi sebagai server yang hanya memberikan layanan kepada client [2]. Client hanya dapat memanfaatkan sumber daya yang disediakan oleh server sesuai dengan otoritas yang diberikan oleh Administrator. Aplikasi yang dijalankan pada sisi client namun hanya bisa dijalankan saat terhubung ke server.

Server bersifat pasif dan hanya kepada client yang mengirimkan request tersebut. Client bersifat aktif mengirimkan request kepada server dan menunggu balasan service yang dikirimkan oleh server [3]. Gambar 1 menunjukan gambar dari system client server. 


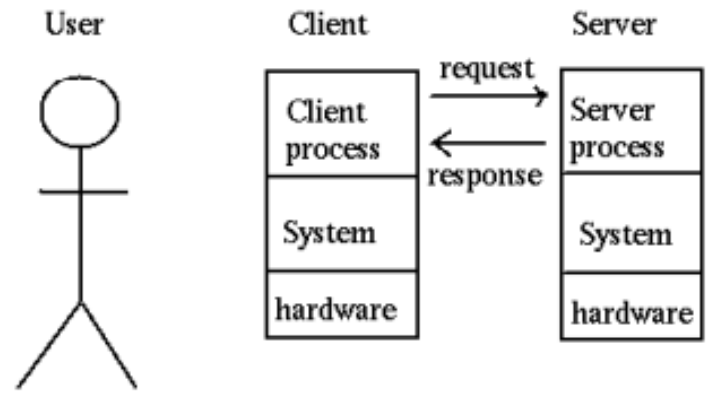

Gambar 1, Client Server.

\section{F. TCP IP}

Apa itu TCP/IP atau Transmission Control Protocol and Internet Protocol adalah sebuah aturan standar yang digunakan untuk komunikasi antar berbagai jenis computer yang terhubung dalam sebuah jaringan computer. Aturan ini diterapkan oleh Defense Advanced Research Projects Agency (DARPA) yang dikembangkan pada akhir tahun 1970-an. Didunia internet computer protocol TCP/IP selalu digunakan, sehingga ini sangat terkenal. Secara umum, komponen dari TCP/IP adalah sebagai berikut :

\section{G. IP Address}

IP Address merupakan sebuah kombinasi unik yang dituliskan dalam angka desima yang dibagi dalam empat segmen. Tiap-tiap segmen tersebut mewakili 8 bit dari alamat yang memiliki panjang 32 bit untuk keseluruannya. Fungsi dari IP Address sendiri merupakan identifikasi setiap host pada jaringan.

Netmask

Sebuah host tidak pernah berdiri namun memerlukan host lain dan bergabung membentuk sebuah Network. Alamat network inilah yang disebut sebagai Network Address. Network Address didapat dengan membuat seluruh bit host menjadi 0 Misalnya ip address 192.168.1.1 dengan IP kelas C, maka network addressnya adalah 192.168.1.0

\section{H. Broadcast Address}

Adalah alamat dimana agar semua host yang berada didalam sebuah network dapat dikirimkan data secara simultan. Gunanya agar apabila ada sebuah host yang ingin mengirimkan data ke seluruh host yang ada disuatu jaringan tertentu, maka host tersebut tidak perlu membuat replica datagram sebanyak jumlah host tujuan karena hal semacam ini akan meningkatkan pemakaian bandwidth dan beban kerja host pengirim.Jadi host pengirim cukup mengirimkan data kealamat broadcast saja maka secara otomatis seluruh host yang ada di sutu network tersebut akan menerimanya.Broadcast address didapat dengan membuat bit host menjadi 1 (kebalikan dari Network Address), jadi misalnya IP addressnya adalah 192.168.1.1, maka broadcasr addressnya adalah 192.168.1.255.

Gateway Address

Adalah alamat IP yang menghubungkan sebuah jaringan dengan jaringan yang lain. Jadi apabila sebuah host ingin berkomunikasi dengan host lain dalam sebuah jaringan yang berbeda, maka host tersebut harus melewati Gateway Address terlebih dahuu untuk mencapai yang satunya.

NameServer Address

Adalah IP milik sebuah server Domain Name Service (DNS) yang bertujuan untuk menerjemahkan sebuah domain menjadi IP address maupun sebaliknya.

\section{Proxy Server}

Proxy server merupakan salah satu server yang posisinya terletak diantara aplikasi dari sebuah server dan juga aplikasi dari sebuah client pada saat jaringan kompter berlangsung dan berjalan. Pada dasarnya, proxy server memiliki tugas untuk menjembatani dan juga mengendalikan aktivitas dari lalu lintas paket data yang melewatinya. Dengan adanya proxy server, maka setiap aplikasi client maupun aplikasi server, seperti FTP, web server, web browser dan semacamnya bisa dimonitor dan juga dikendalikan oleh proxy server. Meskipun seringnya digunakan untuk protocol HTTP dan FTP, squid juga menawarkan dukungan terbatas untuk beberapa protol lainnya termasuk Transport Layer Security (TLS), Secure Socket Layer (SSL), Internet Gopher, dan HTTPS. Versi squid 3.1 mencakup dukungan protocol IPV6 dan Internet Content Adaptation Protocol (ICAP).

Squid pada awalnya dikembangkan oleh Duane Wessels sebagai "Harvest Object Cache", yang merupakan bagian dari proyek Harvest yang dikembangkan di University of Colorado at Boulder. Pekerjaan selanjutnya dilakukan hingga selesai di University of California, San Diego dan didanai melalui National Science Foundation. Squid kini hampir secara ekslusif dikembangkan dengan cara usaha sukarela.

Penggunaan proxy server seringkali dirubah untuk membuat koneksi, terutama koneksi pada jaringan internet menjadi lebih cepat dan juga lebih stabil. Apabila dibandingkan dengan menggunakan koneksi internet biasa tanpa melakukan pengaturan pada proxy 
server. Berbagai jenis jaringan komputer yang ada, proxy server dapat di gunakan untuk semua jenis jaringan sesuai kebutuhan user. mencemari sumu dan sumber air. Hal yang paling sering kita lihat akibat sampah adalah menumpuknya sampah disungai sehingga mengakibatkan banjir.

\section{J. Squid Proxy Server}

Menurut Rusmanto dan Hari Nuryadi (2003:81), Transparent proxy web cache adalah suatu proxy web cache (squid) yang di fungsikan sebagai satu-satunya server. Server ini yang akan menangani semua permintaan halaman web oleh user. Dengan kata lain, transparent proxy web cache akan membajak secara halus traffic HTTP yang umunya menggunakan port 80 untuk memakai port yang dipakai oleh squid secara paksa.

Transparent proxy digunakan untuk memudahkan setting browser client agar memakai proxy secara otomatis. Jika terdapat ratusan atau ribuan computer pada jaringan, maka sangat melelahkan sekali bila browser di tiap client diset satu persatu agar menggunakan proxy.Demikian juga bila harus mengedukasi seluruh user untuk mengubah preferensi dari browser yang digunakan untuk memanfaatkan proxy. Dengan menggunakan transparent proxy, maka permintaan web dari client akan dicegar dan diarahkan ke proxy.Sebuah teknik yang relative lebih mudah dan menyenangkan dari pada cara konvensional.

\section{METODE PENELITIAN}

Metode penelitian yang digunakan oleh penulis adalah :

1. Analisa Kebutuhan

Pada tahap ini penulis melakukan analisa terhadap system jaringan computer yang sedang berjalan di PT.Indomarine. Analisa yang dilakukan meliputi topologi jaringan yang digunakan, spesifikasi perangkat jaringan dan permasalahan yang terjadi. Hasil analisa yang didapat merumuskan terhadap kebutuhan teknologi untuk bisa memberikan solusi terhadap permasalahan yang terjadi.

\section{Desain}

Pada tahap ini penulis merancang system jaringan computer berdasarkan hasil analisa kebutuhan yang telah dilakukan terhadap teknologi jaringan computer yang akan digunakan. Rancangan meliputi topologi jaringan computer, protocol jaringan serta perangkat yang digunakan.

\section{Testing}

Pada tahap ini penulis melakukan percobaan terhadap system jaringan computer yang baru disesuaikan dengan rancangan yang telah dibuat dan melakukan analisa apabila terjadi permasalahan yang terjadi pada saat percobaan sebelum di implementasikan.

\section{Implementasi}

Pada tahap ini system jaringan computer diterapkan dilingkungan perusahaan dan digunakan langsung oleh user yang berwenang.

\section{HASIL DAN PEMBAHASAN}

Topologi jaringan usulan yang penulis gambarkan terhadap jaringan computer yang ada dikantor PT.Indomarine. Adapun rancangan/topologi system jaringan usulannya sebagai berikut :

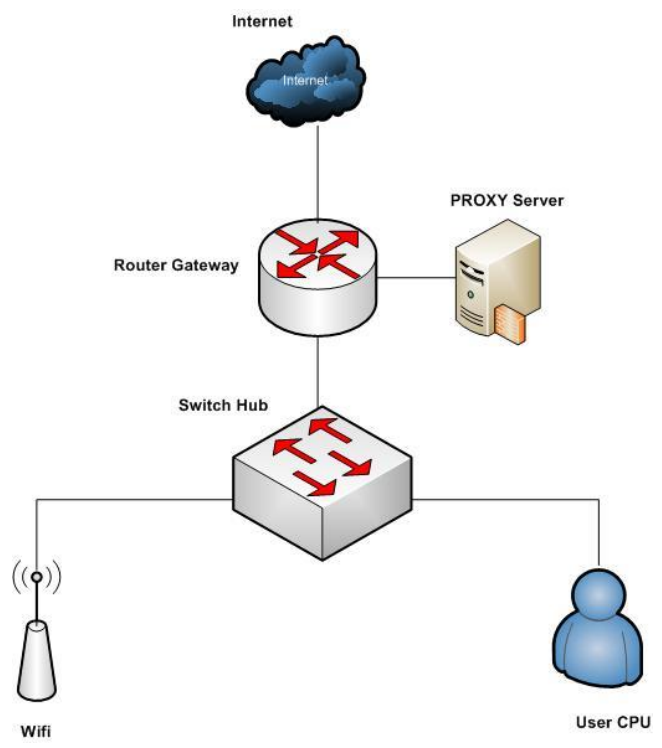

Gambar 1. Topologi Jaringan

Dari topologi diatas bisa dilihat akses internet sebelum ke client akan melewati Router Gateway yang sejajar dengan Proxy Server, selanjutnya paket akan dibelokkan ke proxy server sebelum diteruskan ke user menggunakan distribusi switch hub.

Perbedaan antara skema jaringan berjalan dengan rancangan skema jaringan usulan :

1. Pada jaringan usulan kita dapat dengan mudah menfilter akses internet setiap user, guna untuk membatasi penggunaan internet lingkup PT.Indomarine dibawah level managerial. 
2. Mempercepat akses internet, dengan memanfaatkan fungsi caching pada proxy server.

\section{Instalasi Ubuntu Server}

Berikut langkah-langkahnya :

1. Siapakan 1 unit computer dengan 2 buah LAN Card.

2. Siapkan CD Intalasi linux Ubuntu server.

3. Jika computer kita booting dengan CD instalasi Ubuntu server, program wizard akan memandu kita dalam melakukan tahapan instalasinya.

4. Dalam proses instalasi Ubuntu server, Hardisk computer akan diformat. Jadi, jika kita melakukan bekas yang berisi data penting, pastikan data tersebut sudah dibackup sebelumnya.

5. Berikut ini adalah proses instalasinya :

a. Kita akan diminta untuk memilih bahasa pengantar proses instalasi.

b. Kemudian kita akan diminta untuk memilih wilayah.

c. Kemudian kita akan diminta untuk Proses instalasi, memilih Zona Waktu.

d. Kemudian kita akan diminta untuk memformat Hardisk.

e. Kemudian Ubuntu server mengcopy file ke Hardisk.

f. Proses Instalasi selesai, dan computer akan melakukan reboot.

\section{Konfigurasi Proxy Server}

1. Instalasi Squid Server ketikkan apt-get install squid

2. Setelah squid terinstall mulailah konfigurasi squid ketikkan "nano /etc/squid/squid.conf"

3. Setelah terbuka tekan CTRL $+\mathbf{W}$ cari acl localnet, ketikkan dengan gateway jaringan "192.168.17.1/24"

4. Setelah itu, tekan lagi CTRL $+\mathbf{W}$ dan isikan kata CONNECT method pada pencarian, ketikkan tepat dibawah tambahkan baris "acl terlarang url_reqex -I “/etc/squid/terlarang.txt" ".

5. Setelah itu tekan kembali CTRL $+\mathrm{W}$, lalu isikan dengan kalimat deny manager dan tekan Enter. Maka begitu kalian menekan Enter, kalian akan menemukan http_access deny manager.

6. Setelah itu tekan kembali CTRL $+\mathrm{W}$, lalu cari kata kunci allow localnet.Hapus tanda pagar (\#) yang ada didepan baris \#http_access allow locanet.
7. Selanjutnya tekan kembali CTRL $+\mathrm{W}$, cari kata kunci port 3128 sehingga kalian akan menemukan baris http_port 3128, tambahkan dibelakangnya kata transparent.

8. Tahapan selanjutnya adalah kita akan edit /etc/squid/terlarang.txt dengan perintah nano, isi dengan kata kunci atau web page yang ingin di blok misalnya : xxx.com, malware.com, facebook.com.

9. Terkahir, kita harus melakukan perintah iptables, ketikkan perintah iptables - t nat A PREROUTING -j REDIRECT -p tcp s 192.168.17.0/24 -d 0/0 --dport 80 -toport 3128.

10. Simpan konfigurasi dengan ketikkan perintah iptables-save > letc/network/iptables.conf.

\section{Konfigurasi Access Control List (ACL)}

1. Tekan CTRL $+\mathrm{W}$, cari CONNECT method CONECT, tambahkan perintah
a. acl allow_access src 192.168.17.5
b. http_access allow allow_access
c. acl situs_deny_access url_regex -I "/etc/squid/situs_deny_access.txt"
d. http_access allow situs_deny_access
e. http_access deny all

2. Edit konfigurasi letc/squid/situs_deny_access.txt , disini saya isi dengan konten website .detik.com , .kompas.com.

\section{HASIL UJI COBA}

Dari hasil implemetasi proxy server squid yang dijabarkan pada bab sebelumnya, maka dihasilkan akses control sebagai berikut :

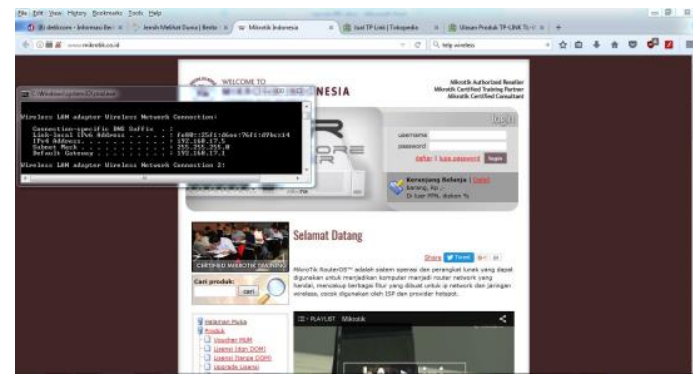

Gambar 2. User Full Akses Internet

Pada Gambar 2 adalah capture dimana IP 192.168.17.5 mendapatkan full akses internet sesuai SOP yang berlaku, bisa kita lihat pada halaman capture user tersebut bisa mengakses halaman website selain acl situs allow yaitu mikrotik.co.id, tokopedia dll. 


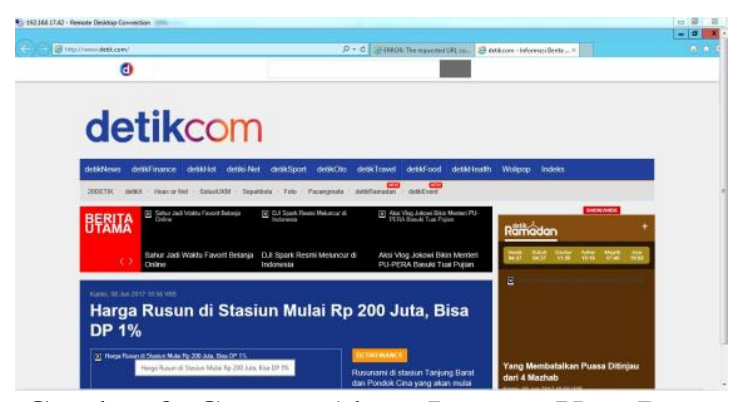

Gambar 3. Capture Akses Internet User Deny

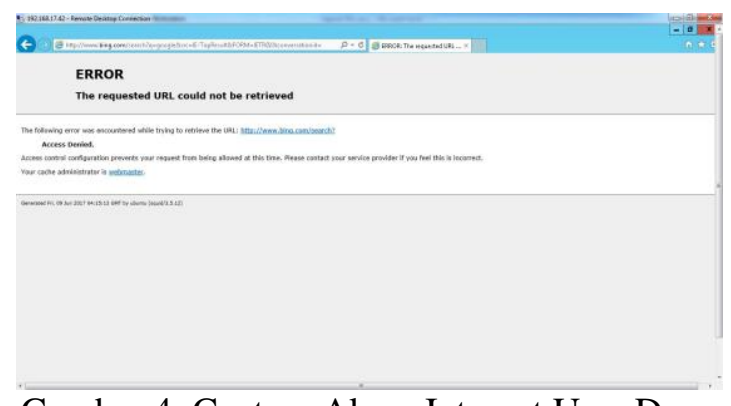

Gambar 4. Capture Akses Internet User Deny

Pada Gambar 3 dan Gambar 4 bisa kita lihat user dengan IP 192.168.17.42 tidak mendapatkan full akses internet sesuai pembatasan yang sudah diatur, user tersebut hanya diperbolehkan mengakses website sesuai list pada /etc/squid/situs_deny_access.txt

\section{KESIMPULAN DAN SARAN \\ Kesimpulan}

Dengan menerapkan Proxy Server, saat ini pengunaan akses internet menjadi lebih terkontrol dan terorganisir, sehingga dapat dilakukan langkah antisipasi guna mencegah penyalahgunaan akses internet dan juga pembatasan sesuai peraturan IT sesuai SOP yang berlaku dalam lingkup PT.Indomarine.

\section{Saran}

Saran yang dapat penulis berikan dalam hal aplikasi animasi adalah :

- Memperbaiki proses inputan, khususnya dalam input alamat IP address agar lebih mempermudah Administrator dalam proses konfigurasi Squid Server berbasis web.

- Agar system yang baru nantinya dapat disiapkan dan disempurnakan secara keseluruhan dan berkesinambungan, maka diharapkan pada pemakai internet dilingkungan perusahaan bisa menggunakan dengan sebaik-baiknya.

\section{REFERENSI}

Firdaus.Ali. (2005). Squid Proxy Server. Ilmiah, 57.

Gunawan.Yan, N. (2012). Multiple Setting Untuk Pengaturan Bandwitch Menggunakan Squid Proxy Server. Teknik Informatika, 3 .

Gunawan.Yan, S. (2012). Multiple Setting Untuk Pengaturan Bandwitdh Menggunakan Squid Proxy Server. Ilmu Komputer Jurusan Teknik Informatika, 101.

Hamdani.Mochammad, S. (2013). Optimalisasi Jaringan Dengan Menggunakan Squid Sebagai Proxy Server Pada Windows XP. Junnal Online ICT STMIK IKMI, 43-44.

P, R. (n.d.). Otomatisasi Acl Squid Proxy Server Berbasis Web. Teknologi Informasi, 49.

Priyono.Denis Tri, P. B. (2013). Membangun Server Proxy Squid Menggunakan Ubuntu Server 11.10 Pada Sekolah Tinggi Keguruan Ilmu Pendidikan PGRI Pacitan. IJNS, 3.

Rahman.Rizal. (2013). Mahir Administrasi Server Dan Router Linux Ubuntu 12.04 LTS. Bekasi.

S.Kom, D. (2015, Oktober 12). Jaringan Komputer. Retrieved April 11, 2017, from dosenit.com: http://dosenit.com/jaringankomputer/teknologi-jaringan/fungsiproxy-pada-jaringan-komputer

Syamsu.Suryadi. (n.d.). Peningkatan Performa Proxy Server Berbasis Squid Dengan Tuning Parameter Konfigurasi. Teknik Informatika, 42.

Yuhandri. (2013). Penerapan Proxy Server Dengan Menggunakan Sistem Operasi Linux Pada Hostpot Universitas Putra Indonesia YPTK Padang. Jurnal Media Procesor, 18-19.

Yuisar, Y. \&. (2015). Analisa Pemanfaatan Proxy Server Sebagai Media Filtering Dan Caching Pada Jaringan Komputer. Media Infotama, 4. 